\title{
DEVELOPMENT OF A WEB-BASED SOCIAL NETWORKING SYSTEM FOR SELF- MANAGEMENT OF DIABETES MELLITUS
}

\author{
Ka C. Chan ${ }^{1}$, Mary B. Martin ${ }^{1}$, Christina Dennis ${ }^{2}$ and Rebecca M. Boschert ${ }^{2}$ \\ ${ }^{1}$ Department of Computer Science and Computer Engineering \\ La Trobe University, Bendigo, VIC, Australia \\ ${ }^{2}$ School of Pharmacy and Applied Science \\ La Trobe University, Bendigo, VIC, Australia
}

\begin{abstract}
This paper presents the design and development of a web-based social networking system for selfmanagement of diabetes mellitus. The objectives of this development are twofold. First is to enable diabetic patients to record and monitor their blood glucose levels by using short message service (SMS) or through a website. Second is to provide social networking functionalities for diabetic patients, healthcare workers, and other related parties to form online communities for information sharing, support, and collaboration. With responsive design, the website aims to provide the best possible user experience across devices from desktops and notebooks to tablets and smart phones.
\end{abstract}

\section{KEYWORDS}

Diabetes, Social Networking, Social Media, Short Message Service, SMS, Telehealth, e-Health

\section{INTRODUCTION}

Diabetes is a serious, chronic condition where poor self-management of blood glucose levels is associated with progression into more complex diseases, incurring significant costs for the health system. In 2012, an estimated 4.8 million deaths worldwide resulted from consequences of high blood sugar [1], often occurring due to poor diabetic management. Between 2005 and 2030, the World Health Organization projects that diabetes deaths will double [2]. With the growing prevalence of diabetes, estimated to affect 347 million people worldwide [2], there will be an increasing demand for effective telehealth solutions.

Current practices commonly involve patients keeping paper records of their blood glucose levels and insulin injections, and discussing that with their general practitioners or healthcare professionals during clinic visits. The blood glucose history of a patient is an indicator to reflect the severity of the disease and how well the condition has been managed and controlled. In the past decade, there has been an increasing amount of literature published on the use of mobileterminal based, SMS based, and web based systems for self-management of diabetes. Past

DOI : 10.5121/ijma.2013.5601 
The International Journal of Multimedia \& Its Applications (IJMA) Vol.5, No.6, December 2013

research indicates that such an approach to diabetes self-management would be both effective and accepted [3,4]. A systematic review of 39 publications describing 28 different studies reported that users generally agreed to the overall concept of these applications [4]. In a meta-analysis amongst 1657 patients from 22 trials, a reduction of HbA1c levels (a longer term measure of glucose control) by a mean of $0.5 \%$ over a median of 6 months was reported due to mobile phone interventions for diabetes self-management [5]. Studies included in this analysis facilitated selfmonitoring and reporting of blood glucose data alongside some sort of management program, intervention, education, and/or continued reinforcement.

It has been suggested that web based management systems can be as effective as face-to-face guidance and treatment in caring for diabetic patients [6]. Where reporting of glucose and other parameters, such as daily exercise and diet, were combined with regular recommendations for individualized diabetes management by a multidisciplinary team, mean $\mathrm{HbAlc}$ improved from $7.5 \pm 1.5$ to $7.0 \pm 1.1 \%(P=0.003)$ after three months [6].

In a recent study Fisher et al [7] investigated the impact of peer support programs in a number of countries that aim to help people manage diabetes and prevent disease associated disabilities. The study identified four key functions of effective peer support - assistance in daily management, social and emotional support, linkage to clinical care, and ongoing availability of support. In another recent study [8], Tao and Or performed a systematic review and meta-analysis of 43 randomised controlled trials evaluating self-management health information technology (SMHIT) for blood glucose control in diabetic patients. The review reported that the use of SMHIT is associated with improved blood glucose control; and the impact is significantly greater when the system is web-based, a mechanism for data entry is provided, and the use of system is not location restricted. These are significant findings valuable to developers who design and develop systems of a similar nature.

Social media sites Facebook and Twitter have taken the world by storm since their launches in 2004 and 2006, respectively. The use of social media has since become part of many people's lives especially among the younger generations. Diabetes as a chronic disease that requires constant and continuous monitoring and management, the "always on" characteristic of online social communities, and "mobility" of mobile devices such as smart phones and tablets greatly enhance the suitability of a social networking platform for self-management of diabetes.

Greene et al [9] carried out a qualitative evaluation on the communication content of the 15 largest Facebook communities dedicated to diabetes. It was found that Facebook provides a forum for diabetic patients to report personal experiences, ask questions, and to receive direct feedback. However, promotional information without accountability or checks for authenticity was also commonly available. In addition to Facebook and Twitter, successful examples of social networking sites developed for focused areas, such as Researchgate for researchers [10], motivated us to develop a social networking site specifically for the diabetes community.

In our previous work [11], we designed and built a web-based system that included features such as SMS glucose level recording, online reporting and group management for medical professionals. With reference to the recent research findings and extending from our previous work, we aim to develop a system with social networking functionalities to facilitate peer support. The website incorporates responsive themes enabling users to use the system from anywhere with all types of devices from desktop and laptop computers to tablets and smart phones. This paper presents the development work including system architecture, development platforms, software 
The International Journal of Multimedia \& Its Applications (IJMA) Vol.5, No.6, December 2013

applications, and the implemented social networking functionalities. We have not found any systems of similar nature reported in the surveyed literature.

\section{SYSTEM ARCHITECTURE}

The overall design of the system architecture is presented in this section. The infrastructure is based on our previous development of a SMS based self-management system for diabetes mellitus [11], and a multi-tenant platform for SMS integrated services [12]. The hardware includes a custom built GSM gateway, a VMware ESXi [13] virtualization server hosting a web server as a virtual machine, and two dedicated database servers. The network diagram is shown in Figure 1.

The GSM gateway is an integral part of the system serving as a bridge between the GSM network and the data network. It was custom designed and built using off-the-shelf components. A special purpose 4-port GSM modem card, the OpenVox G400P [14], was installed in a CentOS Linux [15] server running the open source voice over IP (VoIP) software Asterisk [16]. The gateway is connected to the backend database which stores patients' blood glucose levels and relevant information immediately after they arrive as SMS messages. A more detailed description of the SMS system can be found in [11].

The database server, which also runs on the CentOS Linux operating system [15], was a custom built dedicated server. A physical rather than virtual server was used due to performance issues. The open source MySQL database [17] was used to hold all the user information, and support the operation of the front end website. The database integrated development environment MySQL Workbench [18] was used in the development and administration of the database.

The web server was setup as a virtual machine running Apache on CentOS Linux to host the presented social networking site www.diamond.org.au [19]. The purpose of the site is reflected by its slogan: "A Diamond Community - Managing diabetes made easy." This DIAMOND site was developed based on an open source content management system Drupal [20] and the add-on social business software Acquia Drupal Commons [21, 22], which provides the social networking functionalities to the system. The Drupal Commons base was customised and integrated with the SMS gateway in this work.

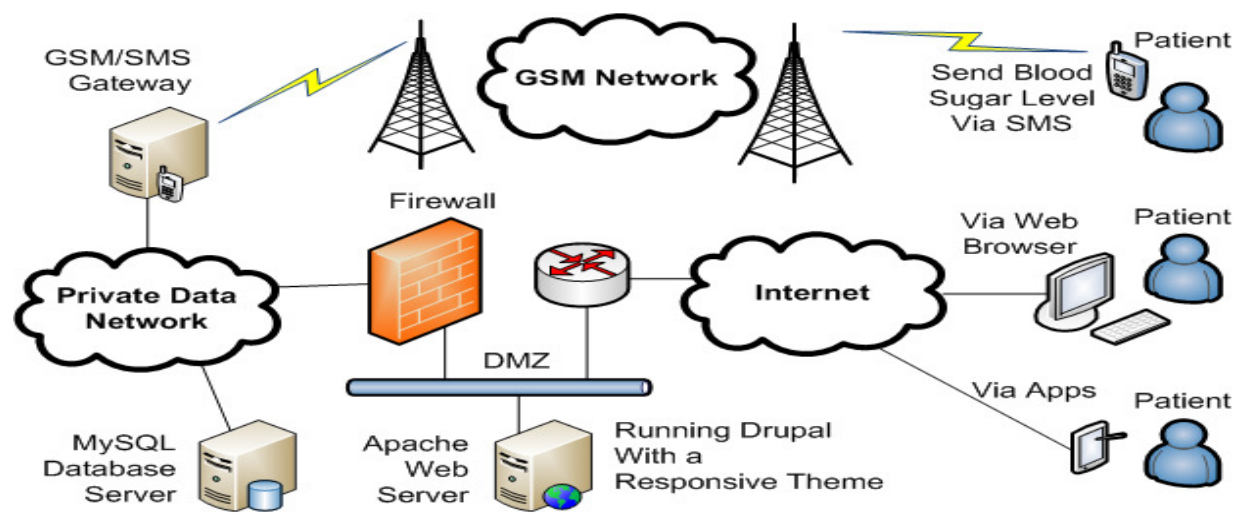

Figure 1. System architecture 
The International Journal of Multimedia \& Its Applications (IJMA) Vol.5, No.6, December 2013

\section{SOCIAL NETWORKING SITE DEVELOPMENT}

Drupal Commons enables developers to build compelling community sites on the Drupal platform. Drupal Commons was built on an adaptive theme base; and therefore, makes it easy to develop responsive websites. According to the screen size of the user device, a responsive website displays different layouts and tiles in order to give the user the best possible user experience. The responsive displays for desktops and smart phones are shown in Figure 2. As Drupal Commons was developed with industry best practices, most users find the DIAMOND site easy to use, and features familiar. The main features will be presented in the following sections.

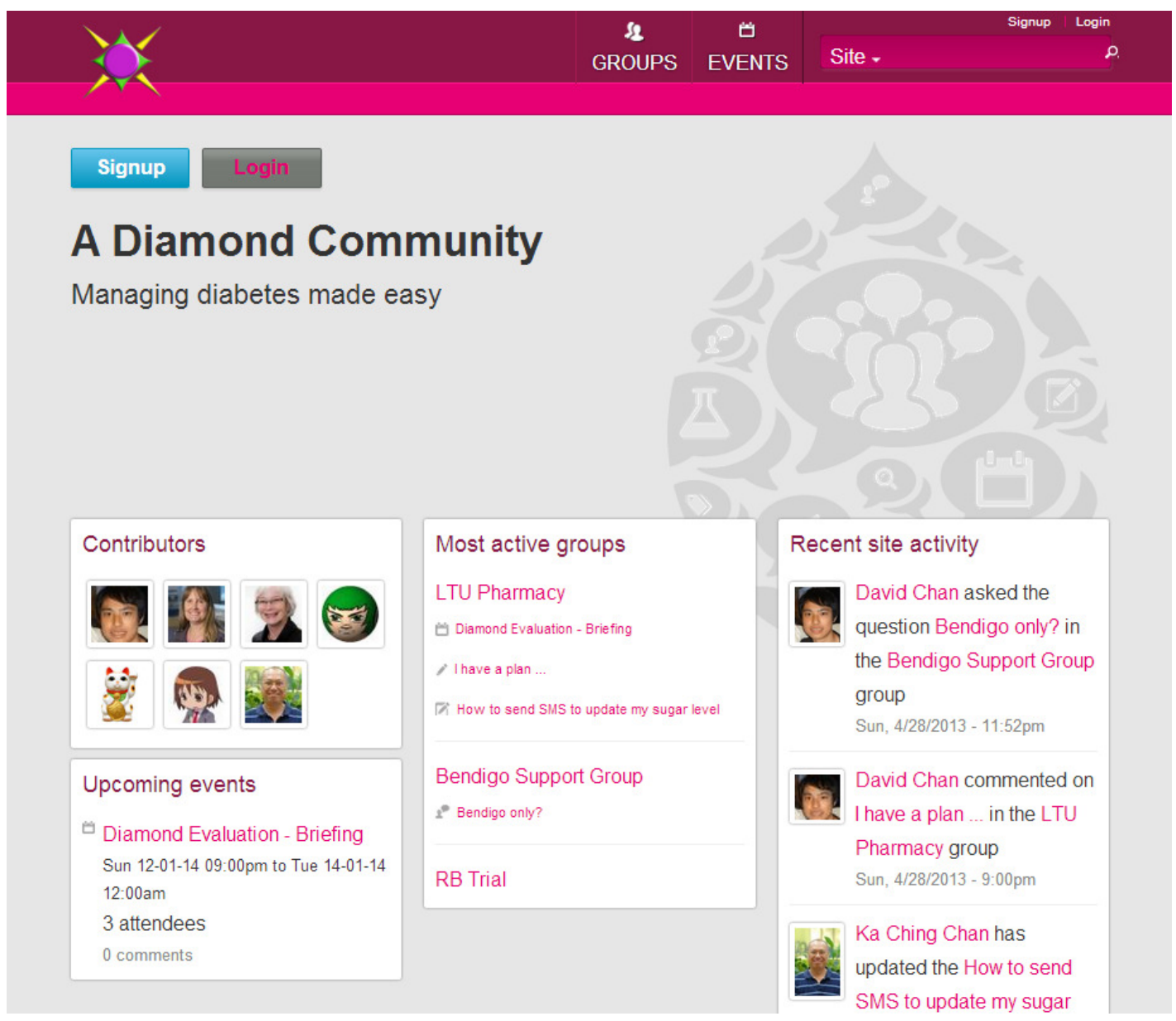

Figure 2. Responsive themes

The installation of Acquia Drupal Commons is a straight forward process for any experienced Linux system administrator. Our system was setup as a VMware virtual machine allowing us to easily provide additional resources in the future as demand grows. The first step was to install the Linux operating system with the required packages including the Apache web server, PHP programming language support [23], and MySQL database server. Then we downloaded, unpacked, and installed the Drupal Commons package, followed by the last steps of configuring 
The International Journal of Multimedia \& Its Applications (IJMA) Vol.5, No.6, December 2013

Drupal, connecting the Drupal site to the MySQL database, and configuring the Apache server and DNS server to ensure the accessibility of the website from the Internet.

Drupal is a very powerful content management system. There are many add-on modules available on the Internet, enabling developers to design and build websites easily, quickly, and add features to meet their specific requirements. Developers can customise their websites either through the web administration interface or coding using programming languages such as PHP, HTML and CSS. In developing DIAMOND, the main task was to customise Drupal Commons, which includes branding with a new logo, modifying the style sheet files, customising responsive layouts, creating content types, installing new modules to add functionalities, and setting permissions for various types of users. Another major task was to integrate the DIAMOND site with the SMS gateway so patients could enter their glucose levels and store the records in the same database by way of either the website or SMS.

Figure 3 to 5 are typical screenshots of the web administration interface. Figure 3 shows the "MANAGE FIELDS" tab of the "Content types", "Sugar Level" page. "Sugar Level" is a content type that we created for recording the blood glucose levels of diabetic patients. The database fields required were created and setup through this page. The same database table and fields are used to record blood glucose levels regardless whether they are received via the website or SMS.

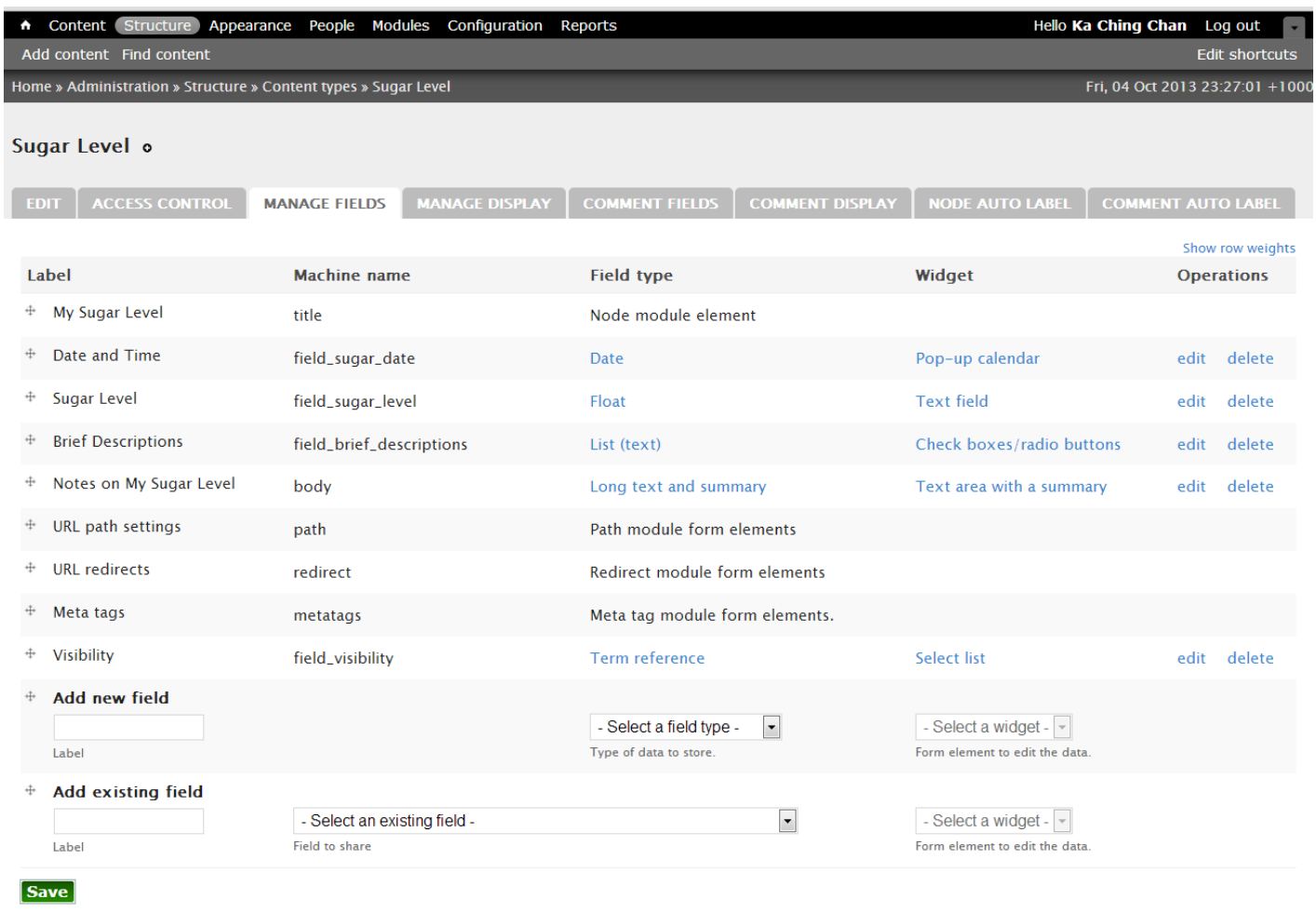

Figure 3. Managing fields through web administration interface

Figure 4 shows the module page for adding, enabling/disabling and uninstalling modules. In this particular example we used the filter list to find the modules related to content access. After successfully installing these content access modules, the page shown in Figure 5 became 
The International Journal of Multimedia \& Its Applications (IJMA) Vol.5, No.6, December 2013 available and made the process very easy to manage the access by different types of users of the content type sugar level.

$\begin{array}{lllll}\text { A Content Structure Appearance People Modules Configuration Reports } & \text { Hello Ka Ching Chan Log out } \\ \text { Add content Find content } & \text { Edit shortcuts }\end{array}$

\section{Modules • \\ LIST UPDATE UNINSTALI}

+ Install new module

All 141 of 23

Access control

Acquia Network

Connector

Administration

Apache Solr

Chaos tool suite

Charting

Charts

Commons

Commons - Building

Blocks

Commons - Content types

Commons - Landino

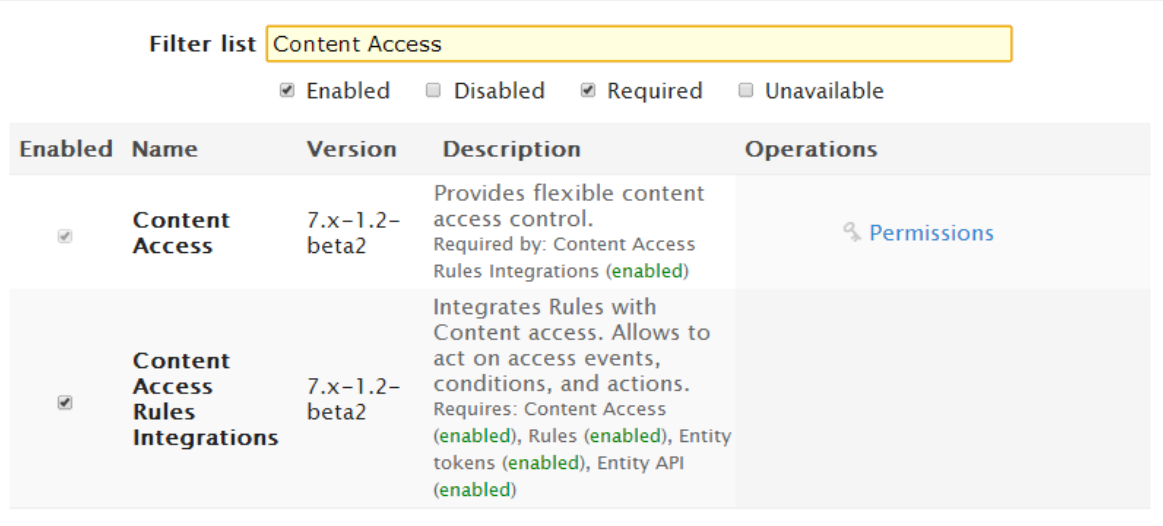

Filter list Content Access

$\checkmark$ Enabled $\square$ Disabled Required $\square$ Unavailable

Provides flexible content

Provides control.

Rules Integrations (enabled)

Integrates Rules with

Content access. Allows to

enabled), Rules (enabled), Entity

(enabled)

Figure 4. Installing and enabling new modules through web administration interface

Figure 5. Setting up access control through web administration interface 
The International Journal of Multimedia \& Its Applications (IJMA) Vol.5, No.6, December 2013

\section{SYSTEM FUNCTIONALITIES}

The system functionalities of DIAMOND from users' perspectives are presented in the following sub-sections.

\subsection{Recording of Blood Glucose Level}

The DIAMOND system aims to provide users with simple, easy, convenient, familiar, and modern user interfaces across all types of devices. Figure 6 shows the web interface displayed on a typical Android phone. The three parts are shown continuously when swiping down the screen. For minimum data entry, a user simply clicks on the "SUGAR" button at the top, enter the sugar level, and press the "Save" key. However, the interface also allows a user to change the time of record, choose a brief description, and enter notes if required.

For users who want to submit data via SMS, they can provide their mobile phone numbers in their profile pages to link the SMS records to their accounts. With the mobile phone numbers linked, users simply send SMS messages with the blood glucose levels as contents to the GSM gateway. The DIAMOND system automatically picks up the originating mobile phone numbers, and inserts the records with the time stamps into the linked user accounts. The limitation of using SMS is the cost associated with it, and GSM gateways will need to be setup in each country to allow users to send SMS messages to a local phone number.
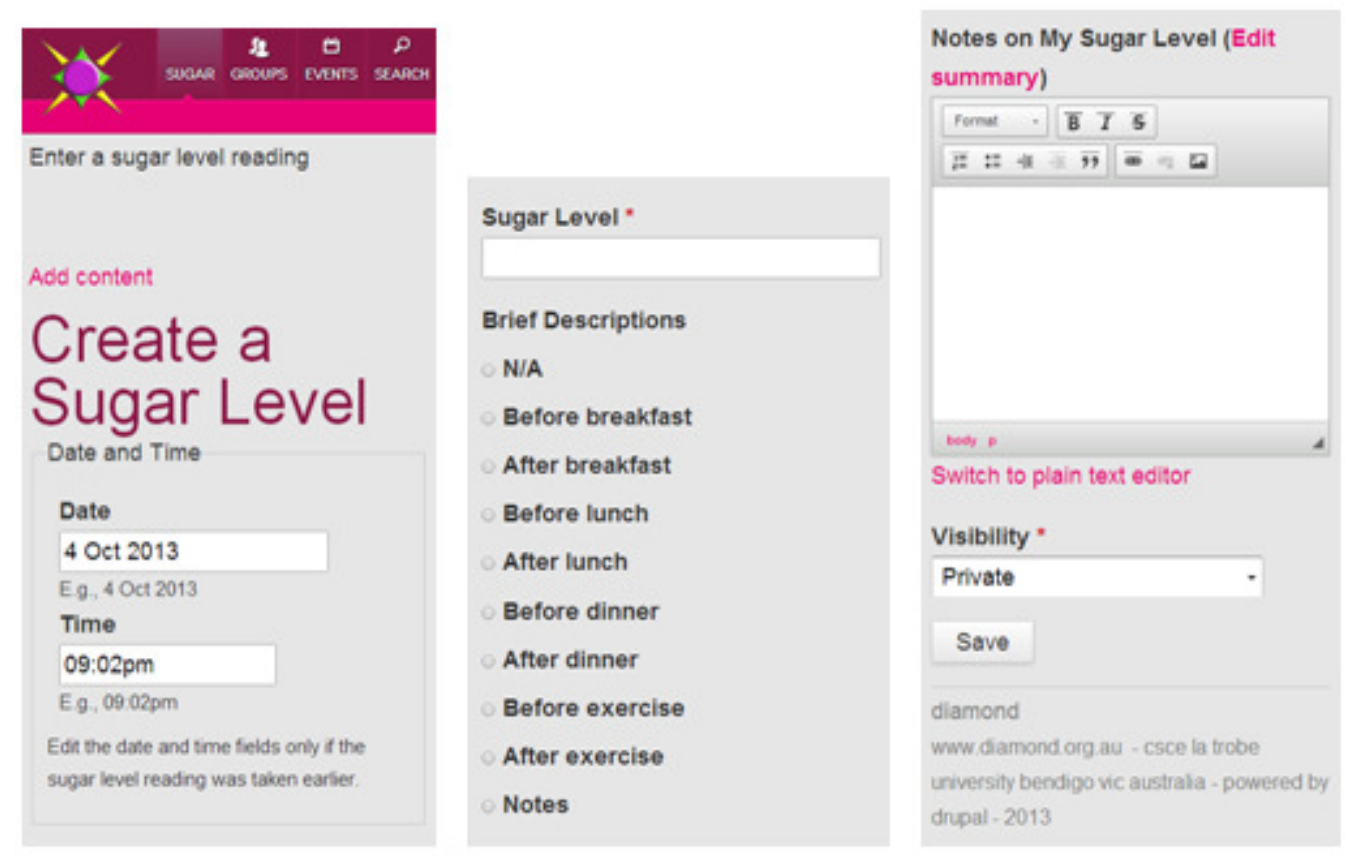

Figure 6. Entering blood glucose records via smart phones

As the blood glucose level is the most important information for a diabetic patient to monitor and manage their condition, the most recent blood glucose levels are always displayed at the most prominent place, i.e. the top and first block, when a user logs into the DIAMOND site. Figure 7 
The International Journal of Multimedia \& Its Applications (IJMA) Vol.5, No.6, December 2013

shows the screenshot of the main page after login. For a smart phone, the "Recent site activity" block will be displayed below instead of on the right of the blood glucose block.

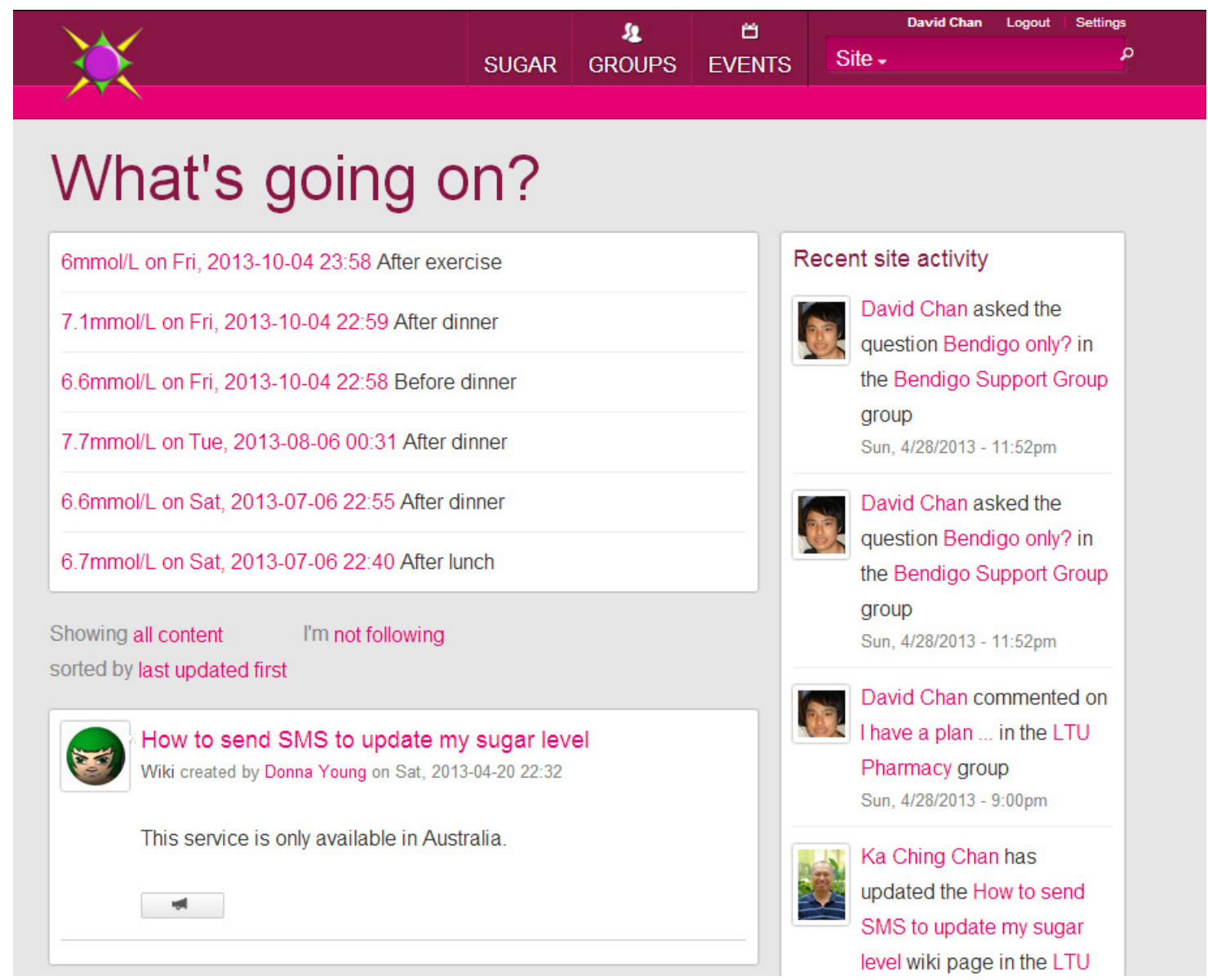

Figure 7. Displaying the blood glucose records in a prominent place

\subsection{Groups and Group Functionalities}

The DIAMOND site provides a modern social networking platform for users to form online communities or groups. The group concept is core as most of the activities and functionalities are performed within groups. All users, from patients to families and friends, healthcare workers, general practitioners, to specialists are allowed to build their own communities and subcommunities, for purposes such as sharing information and knowledge, collaborating, listing and attending events, forming peer support groups, providing healthcare service, conducting polls, and so on. The DIAMOND site offers users high flexibility in forming groups to serve different purposes, and choosing what group activities to participate in and contribute to.

Figure 8 shows the web page for group creation. Any user can play the role of a group administration to start a new group, public or private. Public group contents are visible to everyone; and membership can be added by the group administrator or requested by a user without authorisation. Alternatively, a user can automatically become a group member by posting content in a public group. On the other hand, private group contents are only visible to members; 
The International Journal of Multimedia \& Its Applications (IJMA) Vol.5, No.6, December 2013

and membership can be added by the group administration only. Only members are allowed to publish in a private group.

Figure 9 shows the web page of a group named "LTU Pharmacy". The available group functionalities include posts, questions and answers (Q\&A), wikis, and polls. Posts are used for discussions. Q\&As are used for questions and answers. Wiki pages are editable by all members and polls are for simple surveys. The DIAMOND site provides a flexible platform with the above functionalities without any restriction on the contents provided by users. The appropriateness of contents are the responsibilities of the moderators and site administrators. Figure 10 shows the moderation page that moderators use to screen contents.

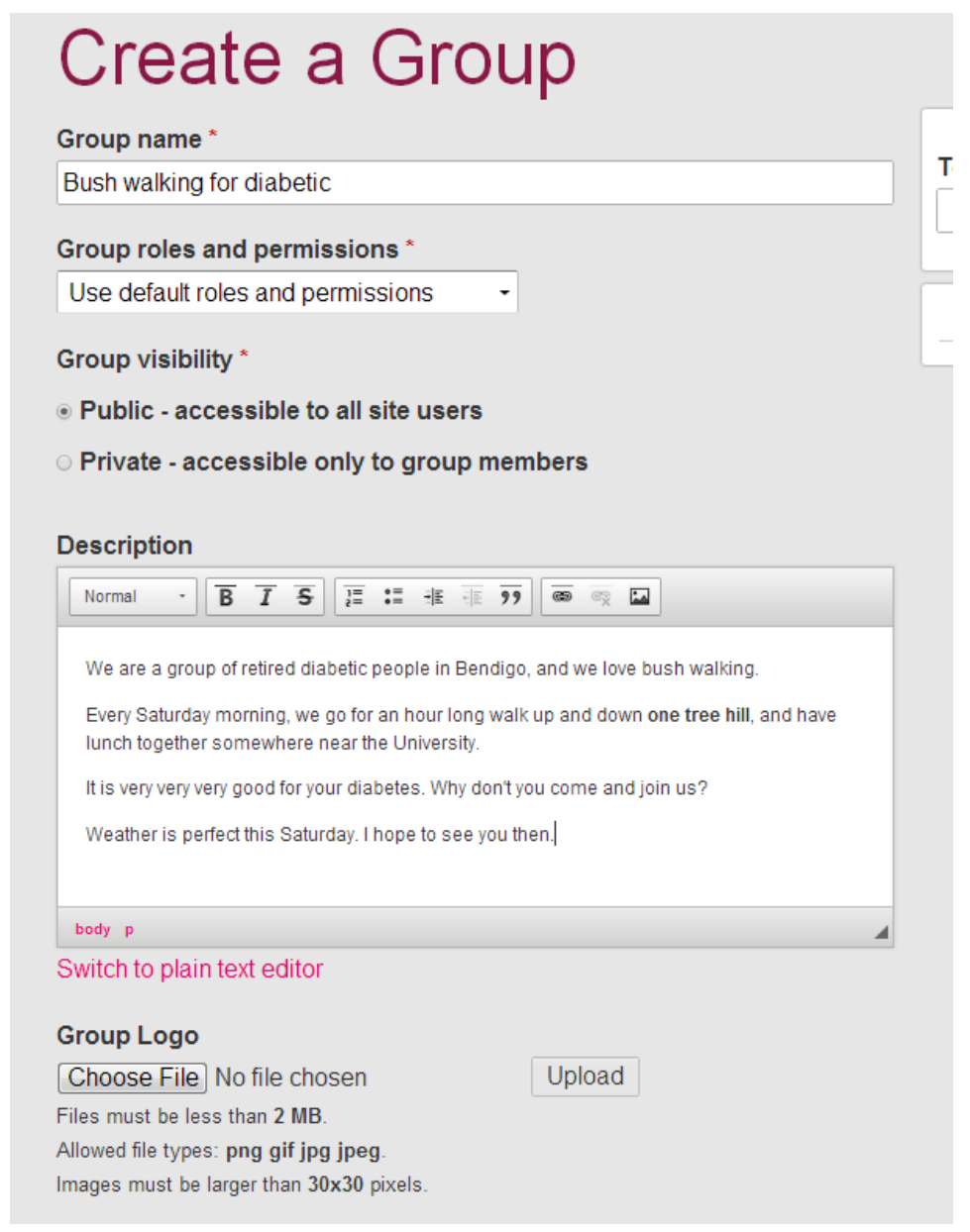

Figure 8. Creating a group

\subsection{Following Things}

The DIAMOND site provides the social networking function of following things of interest. Users choose to follow groups, group contents, people, and topics. Things followed show up in the activity stream block after user login. As an option, users may choose to receive notifications by emails, Figure 11. As shown in Figure 9, DIAMOND supports sharing with social media sites 
The International Journal of Multimedia \& Its Applications (IJMA) Vol.5, No.6, December 2013

such as Facebook, and Twitter. In the user profile page, users may provide their Facebook, Twitter, and LinkedIn URLs.

\subsection{Events}

Another major function that DIAMOND provides is listing events. Any user is allowed to list an event for particular groups, with details including event title and description, date, time, and location. The target group members choose to attend or not, and follow or not.

In summary, simplicity was the key in the development. From user perspectives, we aimed to provide a system that any user could use easily and comfortably without the need for training or even documentation. There are only three options in the main menu - SUGAR, GROUPS, and EVENTS. The SUGAR button only appears after user login. The menu items for all the social networking activities are logically placed at the most appropriate places enabling anyone to use the site intuitively.
LTU Pharmacy
Hi there, this is the La Trobe University's Pharmacy Group
Group roles and permissions:
Use default roles and permissions

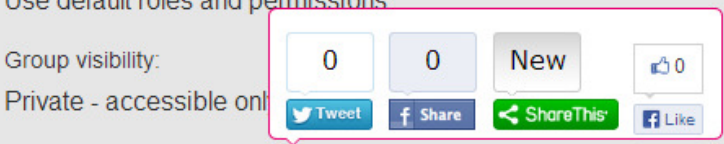
$\triangle$ Follow $\oplus 0 \quad \Delta \quad \Delta$ Report as inappropriate

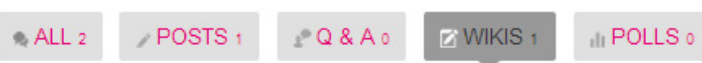
Sort by most recent
How to send SMS to update my sugar level
Wiki created by Donna Young on Sat, 2013-04-20 22:32
This service is only available in Australia.
Upcoming events
Diamond Evaluation - Briefing
Sun 12-01-14 09:00pm to Tue
14-01-14 12:00am
3attendees, 0 comments
Recent activity in this group
David Chan commented on
I have a plan ... in the LTU
Pharmacy group
Sun, 4/28/2013 - 9:00pm
Ka Ching Chan has
updated the How to send
SMS to update my sugar
level wiki page in the LTU
Pharmacy group
Sun, 4/28/2013 - 4:38am
Cat Cohn created Diamond
Evaluation - Briefing in the

Figure 9. Group functionalities 
The International Journal of Multimedia \& Its Applications (IJMA) Vol.5, No.6, December 2013

\begin{tabular}{llrrr} 
\# Content Structure Appearance People Modules Configuration Reports & Hello Ka Ching Chan Log out \\
\hline Add content Find content & & Edit shortcuts \\
\hline Home & & Fri, 04 Oct 201323:36:50+1000
\end{tabular}

Commons Group Moderation 。

\begin{tabular}{|l|l|l|l|}
\hline CONIENT COMMENIS GROUPS MESSAGES REPORTED CONTENT &
\end{tabular}

Proposed Groups Published

-Operations

Publish Delete Item(s)

๑ Title User $\quad$ Updated Operations

- UNSW Diabetes Friendship Group $\quad$ David Chan 2013-07-05 01:13 edit delete

Figure 10. Content moderation

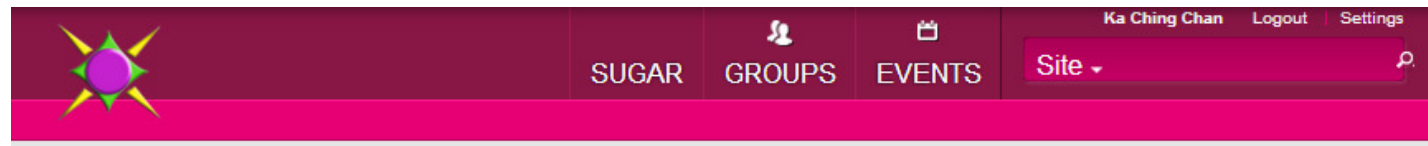

Ka Ching Chan

\section{Notification settings}

\section{\begin{tabular}{l|l|l|l} 
View & Edit profile & Edit account & Notification settings \\
Shortcuts
\end{tabular}}

Control how you are notified of new content and activity. When you follow a group, topic, user, or other content, you'll see updates in your content and activity streams, and you will automatically get email updates unlesss you disable emails or unfollow.

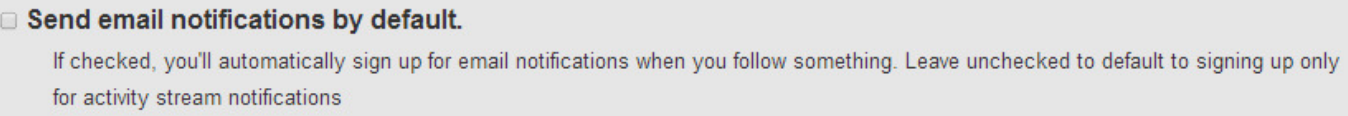

Figure 11. Notification settings

\section{CONCLuSiONS}

We have presented the second stage development of a web-based system for self-management of diabetes mellitus. This work extended our previous work in building a SMS based system to include social networking functionalities with responsive theme base technology, enabling users 
The International Journal of Multimedia \& Its Applications (IJMA) Vol.5, No.6, December 2013

to achieve the best possible user experience across platforms from desktop computers to smart phones.

The next phase of work will include developing iPhone and Android apps, linking to the same database; and investigating the possibilities of adding features for motivational support and including tips and expert advices written by health professionals. We will also conduct trials in which diabetic patients are recruited to use the system and provide feedback for a qualitative study on the effectiveness and usefulness of the system. The results of the study will help identify areas for improvement and further development.

\section{ACKNOWLEDGEMENTS}

We gratefully acknowledge the support and assistance provided by the Computer Science and Computer Engineering Department at La Trobe University, Bendigo. The computer hardware, SMS systems, development platform, and internet infrastructure were donated by an anonymous Sydney based internet solution and service provider. This development would not be possible without their continuous support.

\section{REFERENCES}

[1] International Diabetes Foundation, IDF Diabetes Atlas Fifth Edition (Updated 2013), http://www.idf.org/diabetesatlas, (last accessed 16-Oct-2013).

[2] World Health Organisation (Updated March 2013), Diabetes, http://www.who.int/mediacentre/factsheets/fs312/en/, (last accessed 06-Oct-2013).

[3] Franc, S., Daoudi, A., Mounier, S., Boucherie, B., Dardari, D., Laroye, H. et al. (2011), "Telemedicine and diabetes: achievements and prospects," Diabetes \& Metabolism, vol. 37, no. 6, pp. 463-476.

[4] Tatara, N., Arsand, E., Nilsen, H., and Hartvigsen, G. (2009), "A review of mobile terminal-based applications for self-management of patients with diabetes, in Proc. International Conference on eHealth, Telemedicine, and Social Medicine, eTELEMED '09, IEEE, pp. 166-175.

[5] Liang, X., Wang, Q., Yang, X., Cao, J., Chen, J., Mo X. et al. (2011), "Effect of mobile phone intervention for diabetes on glycaemic control: a meta-analysis," Diabetic Medicine, vol. 28, no. 4, pp. 455-463.

[6] Kwon, H. S., Cho, J. H., Kim, H. S., Lee, J. H., Song, B. R., Oh, J. A. et al. (Dec. 2004), "Development of web-based diabetic patient management system using short message service (SMS)," in Diabetes Research and Clinical Practice, 12th Japan-Korea Symposium on Diabetes Mellitus, vol. 66, Supplement, pp. S133-S137.

[7] Fisher, E. B., Boothroyd, R. I., Coufal, M. M., Baumann, L. C., Mbanya, J. C., Rotheram-Borus, M. J. et al. (Jan 2012), "Peer support for self-management of diabetes improved outcomes in international settings," Health Affairs, vol. 31, no. 1, pp. 130-139.

[8] Tao, D. and Or, C. K. L. (May 2013), "Effects of self-management health information technology on glycaemic control for patients with diabetes: a meta-analysis of randomized controlled trials," Journal of Telemedicine and Telecare, vol. 19, no. 3, pp. 133-143.

[9] Greene, J. A., Choudhry, N. K., Kilabuk, E., and Shrank, W. H. (2010), "Online social networking by patients with diabetes: a qualitative evaluation of communication with Facebook," Journal of General Internal Medicine,vol. 26, no. 3, pp. 287-292.

[10] ResearchGate (2013), https://www.researchgate.net, (last accessed 17-Oct-2013).

[11] Chan, K. C., Wong, L., and Chan, D. B. (2012), "Design of a large scale community-based selfmanagement system for diabetes mellitus," Studies in Health Technology and Informatics, vol. 182, pp. 58-66, 2012. 
The International Journal of Multimedia \& Its Applications (IJMA) Vol.5, No.6, December 2013

[12] Chan, K. C. and Tien, D. (2013), "A multi-tenant platform for SMS integrated services", Int. Journal of Computer Networks and Communications, vol. 5, no. 6, pp. 205-214.

[13] VMware vSphere HypervisorTM (ESXi) (2013), http://www.vmware.com/au/products/vsphere-hypervisor/, (last accessed 6-Oct-2013).

[14] OpenVox: Most advanced Asterisk cards (2013), http://www.openvox.cn/en/products/gsmwcdma-cards/g400p.html, (last accessed 6-Oct-2013).

[15] CentOS, the community enterprise operating system (2013), http://www.centos.org, (last accessed 6Oct-2013).

[16] Asterisk: Open source communications (2013), http://www.asterisk.org, (last accessed 6-Oct-2013).

[17] MySQL: The world's most popular open source database (2013), http://www.mysql.com, (last accessed 6-Oct-2013).

[18] MySQL Workbench (2013), http://mysqlworkbench.org/, (last accessed 6-Oct-2013).

[19] A Diamond Community, Managing diabetes made easy (2013), http://www.diamond.org.au, (last accessed 6-Oct-2013).

[20] Drupal content management platform (2013), http://drupal.org, (last accessed 6-Oct-2013).

[21] Acquia's Drupal Commons - Social Business Software (2013), http://www.acquia.com/productsservices/drupal-commons-social-business-software, (last accessed 6-Oct-2013).

[22] Drupal Commons (2013), https://drupal.org/project/commons, (last accessed 6-Oct-2013).

[23] PHP: Hypertext pre-processor (2013), http://www.php.net, (last accessed 6-Oct-2013).

\section{AUTHORS}

Ka Ching Chan received his BASc in Engineering Science and MASc in Mechanical Engineering from the University of Toronto, Canada, and his $\mathrm{PhD}$ in Manufacturing Engineering from the University of New South Wales, Australia. He was previously a Senior Lecturer at the University of New South Wales, and a Visiting Assistant Professor at the Hong Kong University of Science and Technology. Dr. Chan also had extensive industry experiences as founders and CTOs in growing technology companies from startups to public companies. Dr. Chan is currently a Lecturer in Information Technology at La Trobe University and a Visiting Fellow in Mechatronics at the University of New South Wales. He is currently serving as the Secretary of the IEEE Computer Society, NSW Chapter.

Mary Martin received her BAppSc in Computing from the Bendigo College of Advanced Education, Victoria, Australia and DipAppSc in Medical Radiations and MAppSc from RMIT University, Victoria, Australia. She is a Senior Lecturer in Information Technology at La Trobe University, Bendigo, also providing service teaching in IT to the Pharmacy school at La Trobe and an Honorary Senior Research Fellow at the Collaborative Higher Education and Research Centre (CHERC) based at Bendigo Health's Anne Caudle campus where as a member of a multidiscipline, multi-institution research team, her research is involved with the application of software engineering techniques to healthcare processes.

Christina Dennis received her BSc from the University of Melbourne, and her BPharm and GradDipPharm from the University of Tasmania. Christina is an Associate Lecturer in the School of Pharmacy and Applied Science at La Trobe University with responsibility for undergraduate pharmacy subjects as well as pharmacy Honours projects. Her research interests include chronic diseases, better health outcomes, empowering patients, and the role of technology in education.
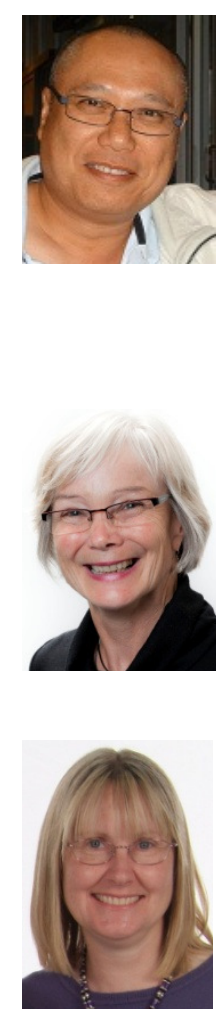
The International Journal of Multimedia \& Its Applications (IJMA) Vol.5, No.6, December 2013

Rebecca Boschert is a final year Bachelor of Pharmacy Honours student at La Trobe University's Bendigo Campus. For her thesis she conducted a qualitative study that evaluated the useful characteristics of the Diamond website. She is interested in all fields of e-Health although the role of technology in the management of chronic diseases such as Diabetes remains the focus of her research interests. As a student Rebecca has performed at an exceptional level being awarded both the 2013 Australian Pharmacy student of the year and the People's Choice Award in a national competition by the pharmacy industry's peak professional body, the Pharmaceutical Society of Australia.

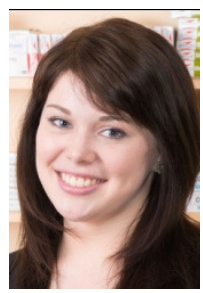

